\title{
It is possible to make patients use braces the hours prescribed: first results from the thermobrace clinical everyday usage
}

\author{
S Donzelli, F Zaina, S Negrini \\ From 8th International Conference on Conservative Management of Spinal Deformities and SOSORT 2011 \\ Annual Meeting \\ Barcelona, Spain. 19-21 May 2011
}

\section{Background and purpose}

Compliance to bracing has been questioned, and temperature sensors advocated to check it. Since 2010 we started the everyday clinical use of a temperature sensor (Thermobrace): aim of this study is to present the results of the first patients.

\section{Materials and methods}

Population: 68 scoliosis consecutive patients $(79 \%$ females, age 14.2 \pm 2.4 ) who accepted to use Thermobrace and had finished at least one period of treatment on the 31st December 2010 [1,2].

Actual hours worn per day were measured; compliance (percentage of prescription) and reported compliance (percentage of hours reported by the patient) were calculated. For reliability purposes, we use two different data processing methods.

\section{Results}

Brace prescription was 16 to 23 hours per day. Average Thermobrace use was $5.25 \pm 2.25$ months. Referred compliance was $94.3 \%$ (range 50-113\%), the real one $86.1 \%$ (range $55-108 \%$ ) or $89.9 \%$ (range $57-111 \%$ ) according to the two different measurement methods. More than half of the patients had at least a $90 \%$ compliance with both readings. No wearing days were $1.0 \%$ of total and involved only $29 \%$ of patients.

\section{Conclusions}

Compliance is neither due to type of treatment, nor to the patient alone. SOSORT criteria for bracing clearly state the importance of the treating team in this respect.

ISICO, Milan, Italy
This is the first study using a temperature sensor in a setting respecting SOSORT criteria, and shows compliance to bracing much higher than what was previously reported. In the everyday clinics, Thermobrace offers a valuable insight to increase compliance even further, and make treatment rely on real data.

Published: 27 January 2012

\section{References}

1. Negrini S, Atanasio S, Fusco C, Zaina F: Effectiveness of complete conservative treatment for adolescent idiopathic scoliosis (bracing and exercises) based on SOSORT management criteria: results according to the SRS criteria for bracing studies - SOSORT Award 2009 Winner. Scoliosis 2009, 4:19.

2. Negrini S, Grivas TB, Kotwicki T, Rigo M, Zaina F: Guidelines on "Standard of management of idiopathic scoliosis with corrective braces in everyday clinics and in clinical research": SOSORT Consensus 2008. Scoliosis 2009, 4(1):2.

doi:10.1186/1748-7161-7-S1-O29

Cite this article as: Donzelli et al:: It is possible to make patients use braces the hours prescribed: first results from the thermobrace clinical everyday usage. Scoliosis 2012 7(Suppl 1):O29.

Submit your next manuscript to BioMed Central and take full advantage of:

- Convenient online submission

- Thorough peer review

- No space constraints or color figure charges

- Immediate publication on acceptance

- Inclusion in PubMed, CAS, Scopus and Google Scholar

- Research which is freely available for redistribution 